\title{
Diagnostic Ultrasonography of Fascitis to Plant. Presentation of a Case
}

\author{
Dayneri León Valladares', Alexis Matheu Pérez², Emilio Villanueva Cagiga1, \\ Alex Pérez León 1 \\ ${ }^{1}$ Institute of Medicine of the Sport, Havana, Cuba \\ ${ }^{2}$ Universidad Bernardo O'Higgins, Santiago, Chile \\ Email: dayneris@infomed.sld.cu
}

Received 14 March 2014; revised 13 April 2014; accepted 12 May 2014

Copyright (C) 2014 by authors and Scientific Research Publishing Inc.

This work is licensed under the Creative Commons Attribution International License (CC BY). http://creativecommons.org/licenses/by/4.0/

c) (i) Open Access

\section{Abstract}

The use of Ultrasonography is very important in the diagnosis of several conditions of the body, particularly the muscular skeletal system, and it is grateful as a very valuable method of exploration complementary of image. The fascitis to plant is frequent in the corridors. The use of the Ultrasonography is with the objective of visualizing the presence and the magnitude of the fascitis plant in a fond corridor and to know the sensibility of the Ultrasonography of High Resolution in the diagnosis of this lesion. This study in a fond corridor, symptomatic of affection to plant fascitis, in this case severe increase of low ecogenicidad of the insert was verified in the calcaneus of the fascia to plant of the tweeted right with bony proliferation sketch at that level, in contrast with the one against-lateral. The Ultrasonography demonstrated its sensibility in the diagnosis of the fascitis to plant that it is recognized as the most frequent affection that is presented in corridors related with the occasional incursion of career or to its systematic practice associated with factors external they predispose.

\section{Keywords}

Sportsmen, A Fond Corridor, Ultrasonography, Lesions, Fascitis, Sport

\section{Summary}

The utility of the Ultrasonography in the diagnosis of many lesions of the Bony, muscular system and to articulate is very well based and it is grateful as a very valuable method of exploration complementary of image. The painful pathology of the plant of the foot owes herself with more frequency to a fascitis to plant. It prevails in the corridors or for some mechanical defect: bad alignment of the foot, obesity or inflammatory processes. With 
the objective of visualizing the presence and the magnitude of the fascitis to plant in a fond corridor and to know the sensibility of the Ultrasonography of High Resolution in the diagnosis of this lesion was carried out this study in a fond corridor, symptomatic of affection to plant, in with severe increase of low ecogenicidad of the insert was verified in the calcaneus of the fascia to plant of the tweeted right with bony proliferation sketch at that level, in contrast with the one against-lateral. The Ultrasonography demonstrated its sensibility in the diagnosis of the fascitis to plant that it is recognized as the most frequent affection that is presented in corridors related with the occasional incursion of career or to its systematic practice associated with factors external they predispose.

\section{Introduction}

The utility of the Ultrasonography in the diagnosis of many lesions of the Bony, muscular system and to articulate is very well based and it is grateful as a very valuable method of exploration complementary of image [1] [2]. The painful pathology of the plant of the foot owes herself with more frequency to a fascitis to plant. It is an inflammation or partial rupture of this fascia and whose causes can be mechanical or traumatic. It prevails in the corridors or for some mechanical defect: bad alignment of the foot, obesity or inflammatory processes. He/she frequently associates to inflammatory processes of the calcaneus [3].

The technique of the exam should be careful, carrying out the mensuration of its grosser near the insert in the calcaneus. Under normal conditions the fascia appears with an echo structure fibrilar and it measures less than 4 $\mathrm{mm}$ of grosser. The low ecogenicidad of the fascia, combined with a grosser bigger than $4 \mathrm{~mm}$, in a symptomatic person, is diagnostic of a fascitis to plant [2] [4] [5].

\section{Objective}

To visualize the presence and the magnitude of the fascitis to plant in a fond corridor and to know the sensibility of the Ultrasonography of High Resolution in the diagnosis of this lesion.

\section{Materials and Methods}

The study was carried out a study Ultrasonography of High Resolution to a fond corridor, symptomatic of affection to plant, using the Team of Digital Ultrasonography of the Institute of Medicine of the Sport, registered Medinson, model INC marks-6000C, with transducers different frequencies of $6.5 \mathrm{MHz}, 7.5 \mathrm{MHz}$, and $10 \mathrm{MHz}$, following the methodology of established exploration for the specialists of the department of Imagenología of this institution [6]: The study of the region to plant of the foot was carried out in prone decubitus, comparatively and with the knees bent. The aponeurosis to plant, hiperecoica, covers the face to plant of the short digital flexor and has a lateral extension that covers the half proximal of the abductor of the 5 to finger. The cuts longitudinal on-line stocking allow to see the fascia plant together to the short flexor of the fingers and to the calcaneus and it allows to measure their thickness [7]-[9].

\subsection{Theoretical Marco-Conceptual}

Muscles of the plant of the foot [10].

In the depth of the aponeurosis to plant, the muscles of the foot prepare in four layers that of the surface to the depth are:

- First layer. Abductor of the fat finger, short flexor of the fingers and abductor of the fifth finger.

- Second layer. Square to plant, lumbricales, long flexor of the fingers and long flexor of the first finger.

- Third layer. Short flexor of the first finger, adductor of the 1er finger and short flexor of the fifth finger.

- Fourth layer. Interoseosplantares and tendons of the long peroneus and of the later tibiae.

\subsection{Arches of the Foot}

These arches provide the support to maintain the vertical position and the propulsion forward. The internal and external longitudinal arches are formed by the bones of the tarsus and of the metatarsus [11]. The internal arch is constituted by the calcaneus, astragals, scaphoids, the three wedges and the medial portion of the three metatarsianos, and it is higher. 
The ligament to plant fixed calcaneus-escafoideo the head of the astragals and it is inserted for before in the scaphoids and from behind in the support of the astragals.

The external lateral arch is constituted by the calcaneus, cuboids' and the two lateral metatarsianos.

The weight of the body is transmitted through the previous and later pillars of the arches of the foot. The later pillars of the medial and lateral arches are the tubers located in the inferior face of the calcaneus while the pillars previous of the medial and lateral arches are formed by the heads of the corresponding metatarsianos [12] [13]. The traverse arch of the foot is constituted by the five metatarsianos and neighboring portions of the cuboids' and of the wedges. Extends from the tuberosidad from the calcaneus to the part previous of the foot and their normal grosser it is of up to $3 \mathrm{~mm}$. [14] [15]. See anatomical of the region to plant of the foot with the transducer in longitudinal court Figure 1.

\section{Results}

Severe increase of low ecogenicidad of the insert was verified in fascia of the calcaneus plant, the foot shows the exostosis, in contrast with the against-lateral Figure 2 [12].

\section{Conclusions}

The Ultrasonography demonstrated its sensibility in the diagnosis of the fascitis to plant that it is recognized as the most frequent affection that is presented in corridors related with the occasional incursion of career or to its systematic practice associated with factors external they predispose.

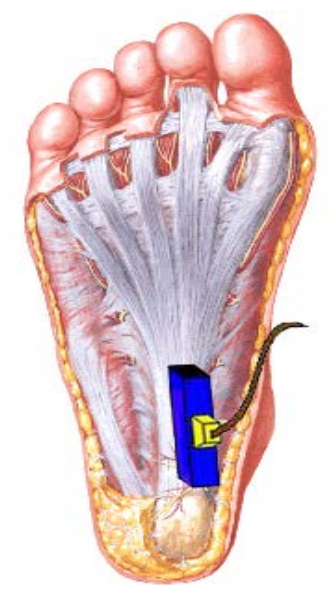

Figure 1. Fascia to plant.

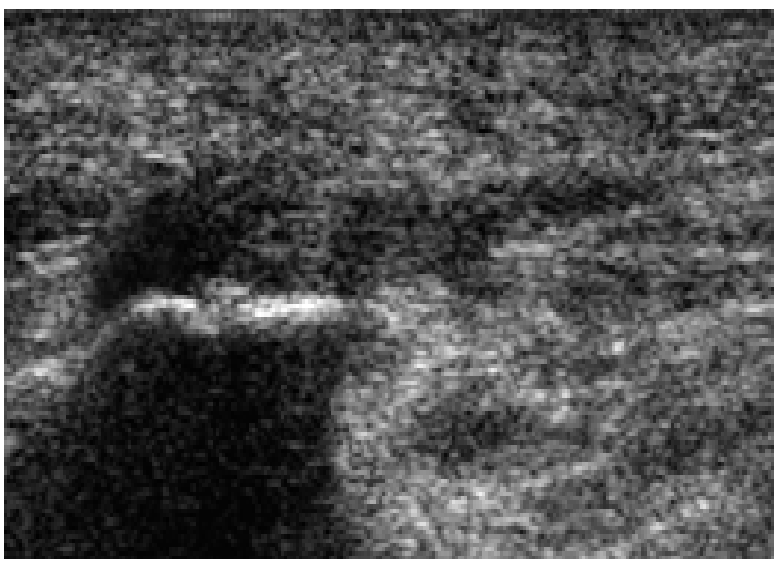

(a)

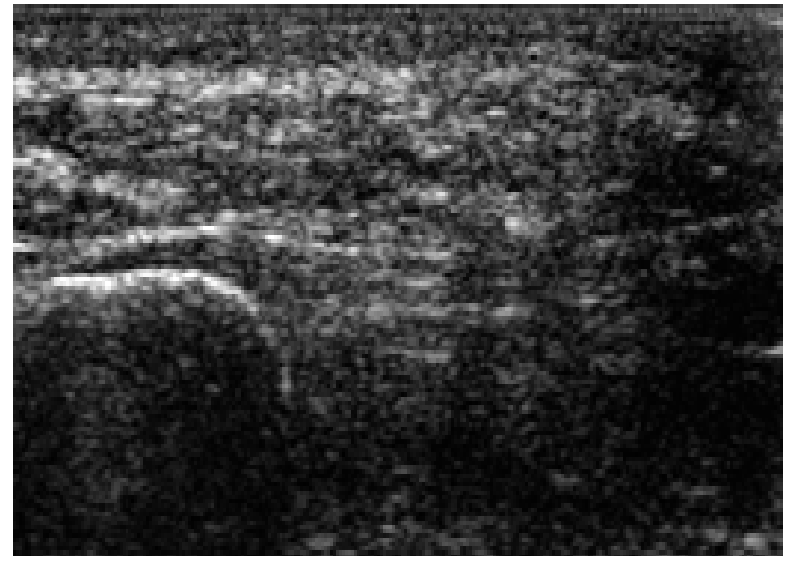

(b)

Figure 2. (a) Region to plant pathological right; (b) Region to plant normal left. 
For their easy accessibility and relative low cost, you can consider to the Ultrasonography like the option image to detect the increase of the fascia to plant in their insert in the calcaneus as well as to visualize exostosis at that level.

\section{References}

[1] Badía, R., Villanueva, E., Roche, H.E. and León, D. (2008) Value of the Ultrasonography in the Exploration of the Knee of Cuban Sportsmen of High Yield. Cuban of Orthopedics and Traumatology, 22.

[2] León, D., Badía, R. and Villanueva, E. (2009) Exploration Ultrasonography of Feet and Ankles in Taekwondistas of the Cuban National Preselection: "The Foot of the Taekwondista”. MEMOIRS III International Convention of Physical Activity and Sports AFIDE 2009, 1121.

[3] Villanueva, E., Badía, R. and León, D. (2009) Diagnostic Ultrasonography of the Fracture of Scaphoids. MEMOIRS III International Convention of Physical Activity and Sports AFIDE 2009, 1137.

[4] De León, A. (2005) Alcance del Ultrasonido Diagnóstico de Alta Resolución en las Lesiones de los Ligamentos Articulares. http://www.infomed.sld.cu/

[5] León, D., Villanueva Cagigas, B.R., Villanueva, E. and Roche, H.E. (2009) Exploration Ultrasonography to Taekwondistas of the Cuban National Preselection. Cuban of Orthopedics and Traumatología, 23.

[6] Hernández, Y., Villanueva, E., Roche, H.E. and León, D. (2011) Exploration Ultrasonography to the Foot of Skaters. Cuban Rev Ortop Traumatology, 25.

[7] Beltran, J. and Rosenberg, Z.S. (1999) Ankle and Foot. In: Stark, D.D. and Bradley, W.G., Eds., Magnetic Resonance Imaging, 3rd Edition, Mosby-Year Book, St Louis, 873-929.

[8] Bencardino, J., et al. (1999) MR Imaging in Sports Reviles of the Foot and Ankle. Magnetic Resonance Imaging Clinics of North America, 7, 131-149.

[9] Brasseur, J. and Tardieu, M. (1999) Accurate Uses of Imaging in Ankle Sprain. The British Journal of Radiology, 82, 63-68.

[10] Fessell, D.P. and van Holsbeeck, M.T. (1999) Foot and Ankle Sonography. Radiologic Clinics of North America, 37, 831-858. http://dx.doi.org/10.1016/S0033-8389(05)70131-7

[11] Gibbon, W. and Long, G. (1999) Ultrasound of the Plantar Aponeurosis (Fascia). Skeletal Radiology, 28, 21-26. http://dx.doi.org/10.1007/s002560050467

[12] Grasel, R.P., et al. (1999) ACR Imaging of to Plant Fascitis: Edema, Tears, and Occult Narrow Abnormalities Correlated with Outcome. American Journal of Roentgenology, 173, 699-701. http://dx.doi.org/10.2214/ajr.173.3.10470906

[13] Jordan, L.K., et al. (2000) Magnetic Resonance Imaging Findings in Anterolateral Impingement of the Ankle. Skeletal Radiology, 29, 34-39. http://dx.doi.org/10.1007/s002560050006

[14] Ledermann, H., et al. (2002) Pedal Abcesses in Patients Suspected of Having Pedal Osteomyelitis: Analysis with MR Imaging. Radiology, 224, 649-655. http://dx.doi.org/10.1148/radiol.2243011231

[15] Lin, J., et al. (2000) An Illustrated Tutorial of Musculoskeletal Sonography. Part III. Lower Extremity. American Journal of Roentgenology, 175, 1313-1321. http://dx.doi.org/10.2214/ajr.175.5.1751313 